\title{
SOBRE (RE)PENSAR A SAÚDE MENTAL E OS PROCESSOS DE DESINSTITUCIONALIZAÇÃO
}

\author{
SOBRE (RE)PENSAR LA SALUD MENTAL $Y$ LOS PROCESOS DE \\ DESINSTITUCIONALIZACIÓN \\ ABOUT (RE)THINKING MENTAL HEALTH AND THE PROCESSES OF \\ DEINSTITUTIONALIZATION
}

\author{
${ }^{1}$ Universidade Federal do Ceará, Fortaleza/CE, Brasil \\ ${ }^{2}$ Clínica Inspire, Fortaleza/CE, Brasil \\ ${ }^{3}$ Universidade Federal da Bahia, Salvador/BA, Brasil
}

Stephanie Caroline Ferreira de Lima ${ }^{1}$, Maria da Conceição Gomes da Silva ${ }^{1}$, Rafaelly Rocha Lima Barbosa ${ }^{2}$ Honorata Dias ${ }^{3}$ e Wilton Bezerra Silva Filho'

\section{Resenha de}

Lima, A. F. (Org.). (2018). (Re)pensando a Saúde Mental e os processos de desinstitucionalização: histórias, intervenções e desafios ético-políticos. Curitiba: Appris Editora.

A presente resenha trata do livro (Re)pensando a saúde mental e os processos de desinstitucionalização: histórias, intervenções e desafios ético-políticos, organizado por Aluísio Ferreira de Lima. A proposta deste trabalho é apresentar, com a colaboração e experiência dos pesquisadores que desenvolvem investigações nesta área há vários anos, capítulo a capítulo, discussões acerca da reforma psiquiátrica brasileira e de serviços substitutivos, a fim de questionar os processos de desinstitucionalização. Tais debates, ainda que partindo de diferentes perspectivas, confluem para a necessidade de uma reforma da Reforma desaguando em ideias possíveis para uma nova práxis ao que se refere à Saúde Mental no Brasil.

O livro tem início com o capítulo intitulado "Os movimentos progressivos-regressivos da reforma psiquiátrica brasileira”. Neste, o autor discorre sobre os processos históricos do movimento de saúde mental, relatando desde o isolamento de indivíduos indesejáveis em 1543 até a Lei 10.216/01, que tornou possível o desenvolvimento de uma "nova' Reforma Psiquiátrica Antimanicomial" (p. 20), bem como a "retomada da autonomia e da hegemonia psiquiátrica, uma vez que a partir dessa lei essa instituição volta novamente a ter leis e portarias especificas para sua organização e financiamento” (p. 20).

Na segunda parte do texto, ele relata sobre os três momentos da Reforma Psiquiátrica brasileira. Em síntese, o primeiro tem como marco inaugural o Movimento de Trabalhadores em Saúde Mental, em 1978, no qual se fazia o questionamento da política de Saúde Mental e pretendia-se garantir direitos dos pacientes. O segundo momento foi o do Movimento de Luta Antimanicomial, que objetivava novos dispositivos de cuidado para promover a desinstitucionalização, a qual o autor ressalva não ser sinônimo de desospitalização. 
O terceiro momento, em que nos encontramos, deu-se a partir da consolidação da Lei 10.216/01, que organizou a Saúde Mental no País por meio de uma política pública que teria como base portarias e leis em prol dos direitos e da autonomia dos pacientes. Contudo, mesmo com conquistas, a Reforma Psiquiátrica ainda encontra desafios para sua efetiva consolidação, pois "seria possível superar a lógica manicomial somente se assumíssemos a subversão da própria concepção de instituição psiquiátrica como saber hegemônico" (p. 25).

Por fim, na última parte do texto, o autor defende que a Reforma Psiquiátrica ocorreu somente em nível instrumental, pois as formas de intervenção ainda produzem estigmatização e medicalização dos sujeitos. Diante disso, sustenta que "somou-se à identidade pressuposta do paciente doente mental, proposta pela instituição psiquiátrica, uma identidade pressuposta do cidadão doente mental, pelos militantes da Saúde Mental” (p. 26). Essa perspectiva é sustentada por uma ideologia que compreende que o "produtor da desumanização do doente mental é o manicômio e a solução para essa desumanização está na ampliação [...] das instituições substitutivas, isto é, dos novos dispositivos de controle" (p. 26), tendo em vista que estes produziriam a inclusão do louco no contexto social. Dessa forma, é possível perceber que, muitas vezes, ainda é sustentada uma prática que não produz uma mudança na realidade.

Para finalizar, o autor enfatiza a importância de se ter uma reflexão crítica a fím de encontrar uma maneira de enfrentar os desafios e efetivar transformações no âmbito da Saúde Mental em nosso país, sendo necessário compreender que a cultura manicomial foi possível devido a uma colonização do imaginário social, a qual estipulou o que era considerado normal e patológico, tornando efetiva a criação de asilos. Torna-se importante compreender, para isso, que a sociedade ainda não superou essa lógica manicomial, uma vez que a atenção ainda se mantém focada no efeito do manicômio nas práticas humanizadoras de inclusão.

No capítulo: "O desobjeto reformista: A reabilitação psicossocial no âmbito da reforma psiquiátrica”, os autores propõem problematizar uma orientação importante da Reforma Psiquiátrica brasileira: a reabilitação psicossocial. Para realizar essa tarefa, utilizam-se do aporte teórico de Michel Foucault, por este ter feito da psiquiatria um tema bastante recorrente em seus estudos e analisar criticamente uma série de dispositivos produtores de verdades e de formas de poder. Segundo os autores, a obra de Foucault poderia ser dividida em dois momentos: no primeiro, foram realizadas uma série de reflexões sobre a loucura e seus processos de alijamento social; no segundo, a loucura passa a ser analisada como dispositivo de poder e de controle sobre os corpos em que o governo liberal passa a incluir os loucos nos cálculos do poder.

Nesse sentido, os autores citam o surgimento da psiquiatria preventiva norteamericana e da psiquiatria de setor francesa, ambas na década de 1950. A primeira consistia em identificar as pessoas com transtornos, em vistas de efetuar intervenções e a segunda, considerada mais progressista, propunha o tratamento dos loucos em seu entorno social. Sobre esta última, mencionam que Robert Castel (1987) alertou para o perigo de responsabilização individual do louco, deixando-o entregue ao seu próprio destino.

No caso do Brasil, a Reforma Psiquiátrica teria surgido na década de 1970, como parte do movimento que dizia respeito ao campo da Saúde como um todo. Assim, não se discutiu de início a situação dos asilos, mas as condições de trabalho dos profissionais de Saúde, mais especificamente os de Saúde Mental. Na Primeira Conferência Nacional de 
Saúde, realizada em 1987, já se encontravam elementos do movimento reformista, embora, conforme alertam os autores, as questões em pauta eram majoritariamente trabalhistas, com muitos aspectos econômicos levantados, como os gastos com a previdência e a capacitação dos usuários para o mercado de trabalho.

Continuando sua exposição, os autores afirmam que só na Segunda Conferência de Saúde Mental, em 1992, teria surgido a ideia de reabilitação social, em que a vida dos pacientes em sociedade seria o ponto central, desenvolvendo-se assim o cuidado por meio de uma série de dispositivos extra-hospitalares.

Além das Conferências, as Leis 8080/1990 e 10216/2001 vêm firmar os pressupostos da Reforma Psiquiátrica brasileira. A primeira, ao instituir o SUS (Sistema Único de Saúde), apresenta em seus artigos elementos básicos que passam a constituir a reforma, tais como: tratamento com participação da comunidade, preservação da autonomia dos usuários, assistência integral, regionalização e uma rede de atendimento hierarquizada. A segunda vai tratar especificamente da Reforma Psiquiátrica. No contexto dessas leis é que surge o termo "reabilitação social".

Para os autores, a proposta do movimento reformista da restauração de uma suposta cidadania perdida traz implícita a ideia de reajuste social, acenando que existiria uma Razão universal e que fazer o louco recuperar essa razão seria o pressuposto da reabilitação social.

Concluem que questionar a reabilitação psicossocial não pretende desqualificá-la ou diminuir sua relevância na vida dos sujeitos em sofrimento psíquico. Almejam, portanto, a partir das ferramentas de análise de Foucault, atentar para o perigo a que aquelas podem conduzir, como à medicalização do social e à flexibilização de novas formas de controle que atendam ao modo de governabilidade liberal.

No capítulo "A nova cronicidade em questão: desafios para os centros de atenção psicossocial como serviços substitutivos”, os autores trazem um tema que tem se constituído um desafio para a construção dos serviços substitutivos ao modelo asilar: os processos que podem criar novas formas de institucionalização e cronicidade. Os autores procuraram, a partir das discussões teóricas de Pepper et al., 2000, Desviat et al., 1986, e Rotteli et al., 2001, e de pesquisa empírica em um CAPS (Centro de Atenção Psicossocial), investigar a existência desse fenômeno na perspectiva dos usuários, familiares e técnicos, objetivando identificar elementos que evidenciassem a possibilidade dessa "nova cronicidade".

Com a pesquisa, os autores identificaram quatro grupos de usuários que estão conectados com o conceito estudado. O primeiro, formado por aqueles que são parcialmente vinculados ao CAPS, de maneira pontual, com o intuito de obter vantagens como a consecução de medicação. Eles "circulam” pelo serviço sem utilizá-lo de forma resolutiva, constituindo o que Pepper et al. (2000) denominaram de "pacientes adultos jovens crônicos". Seriam pacientes com severa dificuldade de acompanhar o funcionamento social e com uma tendência a usar os serviços de forma inapropriada.

O segundo grupo é constituído por aqueles usuários vinculados ao serviço há muito tempo, tidos como pacientes-problema. São polêmicos, desafiadores, evidenciam as falhas do serviço e levam os técnicos a avaliarem suas demandas como consequência do caráter patológico da doença mental. Na classificação de Desviat et al. (1986), seriam os "usuários crônicos dos ambulatórios". 
O terceiro é formado por aqueles que provêm de longas internações e passam por um longo processo de vinculação e adaptação ao CAPS. Apresentam-se como um grande desafio e constituem o que Desviat et al. (1986) apontam como "remanescentes institucionais", evidenciando a persistência da cronicidade e pondo em xeque qualquer possibilidade terapêutica.

O quarto grupo refere-se àqueles que são excessivamente vinculados ao CAPS, que participam de todas as atividades, revelando uma total dependência em relação a eles. Estes caracterizam os pacientes que Rotelli et al. (2001) identificam como os "novos crônicos" resultantes da hiperespecialização e refinamento das técnicas de intervenção. Em outras palavras, a oferta de diversas atividades dentro dos CAPS pode contribuir para reforçar a institucionalização e gerar relações de tutela e dependência dentro dos serviços substitutivos.

A pesquisa dos autores aponta que usuários, familiares e técnicos chegam a persistir na ideia da psiquiatria tradicional, de que a clientela dos serviços seria essencialmente crônica. Contudo, ressaltam também que alguns profissionais reconhecem que, muitas vezes, através de suas práticas, reforçam essa dependência nos usuários.

Outro ponto enfatizado pelos autores são as perspectivas opostas encontradas dentro do próprio CAPS. Ao mesmo tempo em que podem libertar, possibilitar a autonomia, a cidadania e o protagonismo, também podem promover segregação e cronificação. Para finalizar, mesmo admitindo as limitações da pesquisa em relação ao número de entrevistados, os autores não deixam de reconhecer sua importância, no sentido de haver um reconhecimento dos riscos de institucionalização nos serviços substitutivos e que a elaboração de uma crítica como essa pode se constituir em elementos de mudança para a transformação efetiva do modelo de atenção à Saúde Mental.

No capítulo "A utopia da humanização: relato de um hospital psiquiátrico de Minas Gerais”, Maria Stella Brandão Goulart e Flávio Durães apresentam práticas do primeiro hospital psiquiátrico público de Belo Horizonte, o Instituto Raul Soares, as quais são consideradas vanguardistas, a partir da história oral apresentada por funcionários e pesquisadores que à época trabalhavam e/ou faziam residência nessa instituição asilar, assim como em consonância com os Movimentos Antipsiquiátricos pioneiros no estado.

Os autores apresentam iniciativas micropolíticas e autocríticas que proporcionaram projetos contestatórios ao modelo hegemônico dos anos de 1960, 1970 e 1980, tais quais: o Ambulatório Central Roberto Resende; a Residência de Psiquiatria; o Projeto Guimarães Rosa; e o Hospital-dia público pioneiro no estado de Minas Gerais. Ressaltam que houve a intenção de humanizar o tratamento e apontam que os questionamentos levantados em pesquisas e discussões possibilitadas por esses projetos, detalhados um a um nesse capítulo, foram relevantes no contex to histórico anterior à Reforma Psiquiátrica. Em seguida, fazem a ressalva de que não se deve esquecer das contradições e denúncias referentes ao Instituto Raul Soares, senão mostrar que houve iniciativas reformistas.

Na sequência, Daniela R. Schneider, Cristiane Budde, Jane M. Lopes, Karla C. Flores, Rafael Pereira e Eliane R. T. Torres apresentam o resultado da pesquisa realizada na Universidade Federal de Santa Catarina, no Núcleo de Pesquisas em Psicologia Clínica (PSICLIN), em capítulo intitulado "Políticas de Saúde Mental em Santa Catarina nos anos 1970: vanguarda na psiquiatria brasileira?". Descrevem o contexto histórico da suposta desospitalização do Hospital Colônia Santana, marcado pelo embate entre críticas ao 
modelo asilar e o plano governamental desenvolvimentista brasileiro, com enfoque na gestão estadual de Colombo Salles, entre 1971 e 1975.

Por meio de análise documental, realização de entrevistas com profissionais do campo da Saúde Mental de Santa Catarina e a análise de literatura especializada acerca do período mencionado, demonstram que, apesar do pioneirismo à crítica do modelo manicomial, a Colônia Santana permaneceu funcionando conforme uma lógica de "psiquiatrização do social”, o que culminou no crescente número de internações e na continuidade de práticas de controle dos pacientes, chegando à conclusão de que há contradições veladas atualmente, concernentes à lógica preventista comunitária instalada neste hospital psiquiátrico.

As autoras Ana Karenina M. A. Amorim e Magda Dimenstein, do capítulo "Desinstitucionalização em saúde mental e práticas de cuidado no contexto do serviço residencial terapêutico no Rio Grande do Norte", apontam o processo da Reforma Psiquiátrica no contexto brasileiro, ainda em construção, bem como os impasses que dificultam o processo de desinstitucionalização nessa realidade, a fim de sua efetiva concretização.

Diante desse processo de Reforma Psiquiátrica, as autoras se propõem a analisar o Serviço Residencial Terapêutico (SRT) em Natal, implantado em maio de 2005. Estes SRTs visam a "oferecer condições de vida para aqueles com histórico de longas internações psiquiátricas, moradores de rua e egressos de instituições penais e manicômios judiciários" (p. 146), sendo assim uma importante ferramenta no processo de desinstituicionalização, desconstruindo a loucura como forma de aprisionamento. Contudo, as autoras problematizam principalmente a maneira como as práticas de cuidado produzidas podem constituir novas formas de vida para os usuários, bem como podem se encontrar capturadas pela lógica manicomial, restringindo a construção de vida para além dos muros institucionais.

Ao longo do capítulo, as autoras discorrem sobre os impasses que dificultam o processo de desinstitucionalização. Para tanto, elas se propõem a trabalhar com os conceitos de "território", "rede", "biopoder" e "sociedade de controle", analisando suas implicações e relações no contexto de atenção à saúde mental. Após discorrerem sobre esses pontos e compreender que o SRT deve buscar alternativas de cuidado que estão além do modo instituicionalizado do CAPS, as autoras trabalham na perspectiva da desconstrução dos modos de morar e clinicar em relação à cidade. Utilizando os referenciais de Baptista (2005), elas consideram a cidade como um espaço de subjetivação, tornando possível pensar nas experimentações que podem ocorrer no encontro entre o louco e cidade. Propõem, assim, uma desinstitucionalização das práticas de cuidado. Com essas práticas, a ampliação da clínica ocorreria como uma forma de produção de singularidades, ou seja, uma cartografia dos modos de existir.

O capítulo se encerra com uma resposta a tudo o que foi citado, de forma a conscientizar os profissionais dos desafios encontrados nos SRTs, enfatizando que as transformações dependem de iniciativas macro e micropolíticas, a fim de "viabilizar a circulação desses moradores na vida cotidiana ... produzindo liberdade e vida” (p. 160).

No que se refere ao capítulo intitulado "Primórdios da reforma psiquiátrica no Ceará: dos antecedentes históricos à inauguração do seu primeiro CAPS”, trata-se de uma reconstituição do percurso histórico concernente ao trajeto da saúde mental no Ceará, retomando a todo instante - de forma política, inclusive - a desinstitucionalização dos espaços da Saúde Mental. Os autores apresentam, dentre as nuances do percurso histórico, discussões que intercalam desde o uso dos psicofármacos, a produção dos conceitos de 
loucura e doenças e, consequentemente, a marginalização dessas pessoas, até reflexões acerca da evolução do cuidado e dos novos espaços, territorialidades das quais o louco deveria supostamente ocupar.

Em um movimento de transição na própria História, desde a década de 1920, diversos debates gerados em torno dos modelos socioassistencial e sanitário acerca dos espaços e práticas, é possível questionar, como estas discussões levaram ao que se pratica mesmo no contexto atual. Não apenas se faz presente a discussão sobre territórios, mas também sobre quem pode estar nestes espaços enquanto cuidadores. Nesse sentido, o tex to elabora também o percurso histórico do ensino dentro das universidades no estado do Ceará sobre os métodos e técnicas cabíveis a esse público.

Tomando desde a criação do curso de Psicologia na Universidade Federal do Ceará, de terapia ocupacional na Universidade de Fortaleza e o segundo curso de Enfermagem ainda pela UFC, fatos históricos que se deram na década de 70, destaca-se que aquela foi época importante para o entendimento da produção acadêmica voltada para a saúde mental. $\mathrm{O}$ aporte teórico também se mostra de grande valia, pela elaboração da ideia e da sugestão de uma clínica ampliada como alternativa de cuidar, além de um modelo de atenção psicossocial.

Tomando o capítulo "O modo psicossocial e suas consequências teóricas e práticas na interlocução entre saúde mental e saúde da família”, é possível compreender, partindo do aporte teórico dos autores, como a atenção primária no contexto da saúde recebe o impacto da transição da configuração asilar para um modo de atenção psicossocial do qual recebe o cuidado como linguagem. Vale lembrar que, conforme exposto pelos autores, o termo "modo" refere-se a questões da práxis cotidiana, o que se faz coerente no decorrer do trabalho quando casos são analisados. Tal transição faz com que novas práticas emerjam como necessidade de uma demanda nova de modos de lidar com a saúde mental.

O caráter deste aporte não é apenas voltado para saúde mental enquanto teoria, mas também enquanto políticas públicas, das quais recebe certa luz com o Programa Saúde da Família em diálogo com a saúde mental. Dentre suas vicissitudes, descreve desde um breve resgate histórico acerca da construção das políticas no contexto da Saúde Mental, o que se faz presente quase como uma narração de história, ao longo deste capítulo. Nesse sentido, contribui com questionamentos fundamentais para elaboração do entendimento sobre os desafios de se constituir e implantar um novo modo ao que se refere à saúde mental e as práticas do cuidado em Saúde.

No capítulo "Convocação das práticas "psi” para a legitimação de (id)entidades estigmatizadas: armadilhas e possibilidades”, os autores afirmam que vivemos em um mundo onde as mudanças são constantes e as estruturas sociais se modificam a cada momento, assim como a identidade do sujeito é definida a partir dessas transformações.

Conforme destacado pelos autores, a construção identitária envolve, além disso, a implicação política, devido à maneira como o sujeito se reconhece e é reconhecido. A identidade se sustenta pela fé que determina quem é o sujeito. Ou seja, entre várias personagens que ele pode representar, uma é tida pelo especialista (psicólogo) como totalidade de sua identidade e, por meio desse reconhecimento, o sujeito passa a ser incluído socialmente. Sendo assim, nesse capítulo a psicologia social nos propõe a refletir sobre o papel do psicólogo, principalmente dentro do contexto institucional. Questionam até que ponto o profissional também não é reduzido a uma personagem fetichizada, com relação a sua identidade e a orientação formada pela sua atuação. 
No último capítulo, intitulado "Saúde mental, loucura e diversidade cultural: novos caminhos para a desinstitucionalização e as experiências artístico-culturais no Brasil", o foco é a relação entre a ciência moderna e as culturas tradicionais, no que toca à arte, à cultura e à loucura. Se no campo da Saúde Mental a ciência moderna capitalista desqualifica as heranças das culturas tradicionais populares, criando um certo desentendimento entre diversidade cultural e saúde mental, os autores ressaltam que os direitos humanos possuem relação com a saúde mental, por considerarem o direito como diversidade fundamental e as experiências culturais da Saúde Mental como referências concretas de inclusão social dos sujeitos em sofrimento psíquico. Para tal, coloca-se a importância do pensamento crítico em Saúde, herdado do movimento sanitário desde 1970, para analisar a relação entre a diversidade cultural e saúde mental, permitindo uma crítica ao reducionismo cientificista, para que a saúde passe a ser entendida de forma abrangente, como qualidade de vida, como defesa da vida e como produção da vida.

Partindo das discussões desenvolvidas ao longo dos capítulos do livro, concluí-se que é imprescindível questionar e consequentemente (re)pensar (assim como exposto no título) o modo ${ }^{1}$ proposto pela Reforma Psiquiátrica até o presente momento histórico que vivemos. Com efeito, o entendimento da necessidade de uma reforma da Reforma enquanto possibilidade de repensar as práticas em Saúde mental, parte do interesse compartilhado por muitos, para além dos autores de cada um dos capítulos, no intuito de (r)existir e revolucionar, revendo inclusive territorialidades e espaços de fala dentro do referido contexto.

\section{Nota}

1 Entende-se aqui o termo "modo" como aquilo que se refere a uma práxis ativa no cotidiano como atenção no contexto da Saúde Mental e da Reforma Psiquiátrica. 


\section{Referências}

Baptista, L. A. (2005). Dispositivo Residencial e as Máquinas do Morar. In A. Jacó-Vivela, A. C. Cerezzo, \& H. B. C. Rodrigues (Orgs.), IV Encontro Clio-Psyché: História e Memória (s. p.). Juiz de Fora/MG: Clio Ed. Eletrônicas. Recuperado de http://www.cliopsyche.uerj.br/ wp-content/uploads/anaisivo.pdf

Castel, R. (1987). A Gestão dos Riscos. Rio de Janeiro: Francisco Alves.

Desviat, M., Liria, A. F., \& Olmedo, G. R. (1986). La nueva cronicidad. In J. I. Espinosa (Org.), Cronicidad en psiquiatría (pp. 205-358). Madri: Asociación Española de Neuropsiquiatría.

Lima, A. F. (Org.). (2018). (Re)pensando a Saúde Mental e os processos de desinstitucionalização: histórias, intervenções e desafios ético-políticos. Curitiba: Appris Editora.

Pepper, B., Kirshner, M. C., \& Ryglewicz, H. (2000). The young adult chronic patient: overview of a population. Psychiatric Services, 1(5), 989-995.

Rotelli, F., De Leonardis, O., \& Mauri, D. (2001). Desinstitucionalização, uma outra via. In F. Nicácio (Org.), Desinstitucionalização (pp. 17-59). São Paulo: Hucitec.

STEPHANIE CAROLINE FERREIRA DE LIMA

http://orcid.org/O000-0002-3970-2726

E-mail: stephaniecarolinelima@hotmail.com

\section{MARIA DA CONCEIÇÃO GOMES DA SILVA}

http://orcid.org/0000-0003-1667-2891

E-mail: ceicagomesead@gmail.com

RAFAELLY ROCHA LIMA BARBOSA

http://orcid.org/0000-0001-6348-9788

E-mail: psi.rafaellyrocha@gmail.com

HONORATA DIAS

http://orcid.org/0000-0003-3012-4891

E-mail: diashonorata@gmail.com

WILTON BEZERRA SILVA FILHO

http://orcid.org/0000-0003-1949-3709

E-mail: wsilvapsi@gmail.com

\begin{tabular}{l|l} 
Histórico & $\begin{array}{l}\text { Submissão: 26/07/2018 } \\
\text { Revisão: 03/07/2019 } \\
\text { Aceite: 03/03/2020 }\end{array}$ \\
\hline
\end{tabular}

